$\left.\mathrm{KMnO}_{4}\right)$. We, therefore, at the present time, would assume no greater absolute accuracy for the values obtainable than o.r\%.

The author takes pleasure in acknowledging the kindness of Dr. W. F. Hillebrand in giving valuable advice during the course of the work reported in this article.

BUrEau of Standards, Washington, D. C.

\title{
THE CARD INDEX TO CHEMICAL LITERATURE OF THE UNITED STATES PATENT OFFICE.
}

By EDwin A. HILI.

Received January 9, 1912.

Previous papers, fully describing the system used, have been published in This JournaL, 22, 478 (1900) and 29, 936 (1907), this paper being in the nature of a report of progress, the index now containing about I,200,000 cards, of which 700,000 are chemical titles and names of substances and 500,000 are formula cards. At the present time a force of four persons is at work in keeping up to date with the bimonthly issues of the Abstracts of the Society, which receive a very minute treatment, some of the half and quarter page abstracts in the Organic section at times giving rise to from 50 to 200 cards each, as every substance named is carded. Our force, however, is not sufficient to do all that has been blocked out as desirable, and some work which we hope to do in the future is now in abeyance for lack of force, $e . g$.:

$J$. Chem. Soc. (London); from Igo7 to date.

Supplements to Richter's "Lexikon der Kohlenstoff Verbindungen."

Remaining volumes of "Beilstein."

Wurtz's "Dictionnaire de Chimie."

Watts' "Dictionary of Chemistry" (4-vol. edition).

And some other works which I will not take time to mention, to say nothing of the large number of chemical patents not yet indexed.

For convenience of reference I append a table showing the work done since 1907 (for previous work see the articles already published), so that any one caring to make use of the index can know exactly what is the field covered, which, including the English abstracts to 1907 and o.dr own to date with the exception of Vols. I and 2 , which will eventually be included, is fairly complete.

This index, while intended primarily for the use of the office in the granting of chemical patents, is thrown open to the general public without charge, any one beinga llowed to consult it and make extracts from it without payment of fees, and more than once advanced students of our universities have greatly lightened their labors in the examination of literature in preparing their theses, and its use by patent solicitors and attorneys and chemical engineers in investigating questions of patenta- 
bility, novelty, and patent validity in connection with chemical inventions is becoming quite frequent, while the assistant examiners of the chemical divisions of the office make constant use of it.

Those wishing to make use of it and unable to come to Washington in person can easily arrange to have any of the numerous men of science in Washington do so for them, or through Prof. C. E. Munroe or Asst. Prof. O. D. Swett, of the George Washington University here, could probably arrange to have such work done for them at moderate charges by some of the chemical students in that university, and again the firm of Longfellow and Bitzer, of 622 F. Street, N. W., this city, is one of several firms of local typewriters and stenographers who make a specialty of making copies and extracts fron the various books and records of the Patent Office.

In the table following in the column "How indexed," the legend "Page by page" means an inspection of each page and an indexing of all substances and general titles mentioned; "Index copied" means that the titles in the index are duplicated by typewriter on cards; "Text cut and pasted" means that two copies of the work were obtained and each page cut up into small items and separately pasted upon the cards; "Index cut and pasted" indicates the same treatment of two copies of the index; and "Chem. index copied" means that the chemical portion only of the index was so treated.

\section{PUBlications INDEXED SINCE 1907. Title of publication, etc.}

American Association for Advancement of Science, Reports,

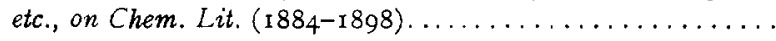
American Chemical Journal (Easton, Pa.), Vols. 24-36 (1900-

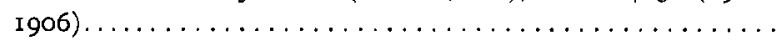
American Chemical Society Abstracts, Vols. 3 and 4 (Igo9-

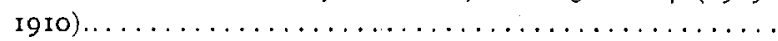

American Electrochemical Society Journal, Vol. 2 (1902)...... Beilstein, F., "Handbook of Organic Chemistry," Vols. I and

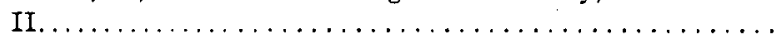

Berichte der deutschen chemischen Gesellschaft, Vols. 3 I to 33

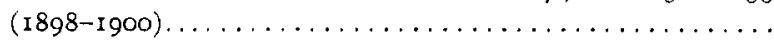
Census, Izth $U$. S. Bulletin 201, "Chemicals and Allied Products" ...........................

Chemical News (London), 2 Vols. for $1900 \ldots \ldots \ldots \ldots \ldots$. Chemical Society (London, Eng.), Collective Index (1873-1882) Chemical Society (London, Eng.), Collective Index (1883-1892) Chemical Society (London, Eng.), Annual Indexes (1893-1907) Clarke, F.W., "Constitution of the Silicates," Bulletin I25, Geological Survey........................ Greenwood Guide to Technical and Commercial Books (1904) Journal of Physical Chemistry, Vols. 4 and 5 (1900-Igor).....

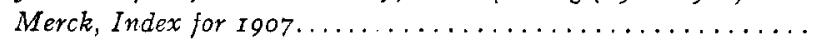
Moissan, "Traité de Chemie Minerale," Vols. I and II

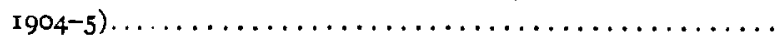

\section{How indexed.}

page by page

index copied

text cut and pasted

index copied

index copied

index cut and pasted

text cut and pasted

index copied

text cut and pasted

text cut and pasted

text cut and pasted

page by page

chem. index copied index cut and pasted page by page

page by page 
Publications INDEXed since igo7 (continued).

Title of publication, etc.

How indexed.

Scientific American, "Cyc. of Receipts, etc.," (1892) (Chem.

Syn.)............................ page by page

Society of Chemical Industry, Collective Index (Vols. I to 14) .. text cut and pasted

Society of Chemical Industry, Vols. I 5 to Ig (I896-1900)....... index cut and pasted

Strecker, A., "Textbook of Organic Chemistry" (1882), pp.

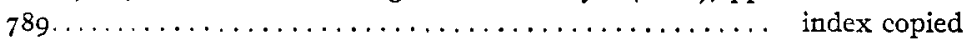

\section{SOME NEW FORMS OF PROJECTION APPARATUS.}

By L. M. DENNIS.

Received December 18, 1911.

The decomposition of water by electrolysis, the union of hydrogen and oxygen to form water, the electrolysis of hydrochloric acid, and other experiments with gases may satisfactorily be demonstrated before small classes by means of the lecture apparatus designed by Hofmann and others. When, however, the audience numbers several hundred, the apparatus is too small to render the details of the experiment clearly visible in all parts of the lecture room.

To obviate this difficulty, the small apparatus illustrated in Figs. I to 5 was designed for the projection of such experiments. Since round

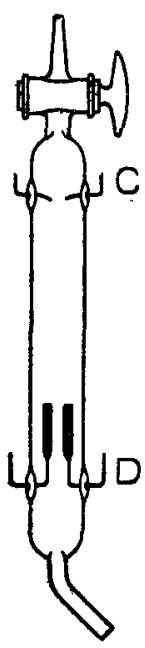
glass tubes are not suited to projection before the lantern, those parts of the apparatus that are to be projected upon the screen are made of flattened glass tubes with the sides as nearly parallel as possible. The main tubes of the apparatus shown in Figs. I, 3 and 4 are $12 \mathrm{~mm}$. wide and $4 \mathrm{~mm}$. thick, while the tube $C$ of Fig. 5 is $28 \mathrm{~mm}$. wide and $\mathrm{I} 4$ mm. thick. As the usual diameter of the condensers of lanterns that are used for projection is about iI cm., the height of that part of the apparatus that is to be projected upon the screen, for example, from the stopcock down to $D$ in Fig. I, is about $9 \mathrm{~cm}$.

Fig. I shows an apparatus designed to illustrate the fact that the gases liberated when water is decomposed by an electric current recombine when the

Fig. I. mixture is ignited by an electric spark and leave no gas residue. The tube is connected with the level tube (Fig. 2) by a piece of small rubber tubing about $25 \mathrm{~cm}$. long, is filled with dilute sulfuric acid, and is held in front of the condenser of the lantern by a small clamp that grasps the tube just below the terminals $D$. The lower terminals are connected with a suitable source of direct current and the terminals at $C$ are

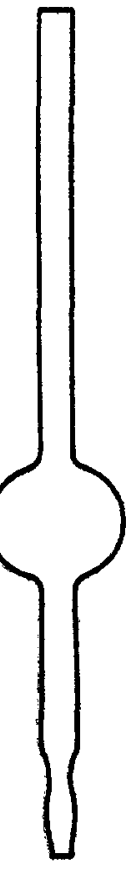

Fig. 2. 